\title{
Para além da instrumentalização: avaliação da aprendizagem na Educação
}

\section{Profissional e Tecnológica}

\author{
Beyond instrumentalization: assessment of learning in Professional and Technological Education \\ Más allá de la instrumentalización: evaluación del aprendizaje en la Educación Profesional y
}

Tecnológica

Recebido: 08/11/2021 | Revisado: 18/11/2021 | Aceito: 08/12/2021 | Publicado: 16/12/2021

Francisco das Chagas de Sena
ORCID: https://orcid.org/0000-0002-3653-9767
Instituto Federal de Educação, Ciência e Tecnologia do Ceará, Brasil
E-mail: Francisco.sena @ifce.edu.br
Francisco das Chagas Silva Souza
ORCID: https://orcid.org/0000-0002-9721-9812
Instituto Federal de Educação, Ciência e Tecnologia do Rio Grande do Norte, Brasil
E-mail: chagas.souza@ifrn.edu.br

\begin{abstract}
Resumo
Este artigo objetiva problematizar a avaliação da aprendizagem na Educação Profissional e Tecnológica. Considerando que a finalidade desta, para muitos, está restrita às demandas do mercado de trabalho, a questão que se coloca é: essa modalidade de ensino deve ter como finalidade o mercado, as demandas do empresariado, ou proporcionar ao educando uma formação que vá além desse objetivo? Para isso, são apresentadas as bases teóricas da instrumentação na educação, oriundas das abordagens tradicionais e tecnicistas, e explicitadas as diferenças entre a cultura da instrumentalização e a da emancipação em relação à avaliação da aprendizagem, posicionando-se em favor desta última como a mais adequada a uma prática docente libertadora. A metodologia é ancorada em uma abordagem qualitativa, com pesquisa bibliográfica e exploratória. Também foram consideradas a atual Lei de Diretrizes e Bases da Educação Nacional, a Base Nacional Comum Curricular e as Diretrizes Curriculares Nacionais para a Educação Profissional e Tecnológica. A partir desses estudos conclui-se que a EPT deve formar para além das demandas do mercado.
\end{abstract}

Palavras-chave: Ensino; Avaliação da aprendizagem; Educação Profissional e Tecnológica; Instrumentalização.

\begin{abstract}
The objective of this article is to discuss the assessment of learning in Professional and Technological Education. Considering that its purpose, for many, is restricted to the demands of the job market, the question is: should this type of education aim at the job market, the demands of business, or provide the student with an education that goes beyond this objective? For this purpose, the theoretical bases of instrumentation in education, arising from traditional and technical approaches, are presented, and the differences between the culture of instrumentalization and emancipation in relation to the assessment of learning are explained, positioning itself in favor of this last one mentioned as the most suitable for a liberating teaching practice. The methodology is based on a qualitative approach, with bibliographical and exploratory research. The current Law of Guidelines and Bases for National Education, the Common National Curriculum Base, and the National Curriculum Guidelines for Professional and Technological Education were also considered. Based on these studies, it can be concluded that the Professional and Technological Education must prepare students for beyond the job market demands.
\end{abstract}

Keywords: Teaching; Learning assessment; Professional and Technological Education; Instrumentation.

\section{Resumen}

Este artículo objetiva problematizar la evaluación del aprendizaje en la Educación Profesional y Tecnológica. Considerando que la finalidad de esta, para muchos, está restricta a las demandas del mercado laboral, la cuestión que se plantea es: ¿qué esa modalidad de enseñanza debe tener como finalidad el mercado, las demandas del empresariado, o proporcionar al estudiante una formación que sea más allá de este objetivo? Para eso, son presentadas las bases teóricas de la instrumentalización en la educación, oriundas de los abordajes tradicionales y tecnicistas, y explicitadas las diferencias entre la cultura de la instrumentalización y de la emancipación en relación a la evaluación del aprendizaje se poniendo a favor de esta última como la más adecuada a una práctica docente libertadora. La metodología está anclada en un abordaje cualitativo, con investigación bibliográfica y exploratoria. También fueron consideradas la actual Lei de Diretrizes e Bases da Educação Nacional, la Base Nacional Comum Curricular y las 
Diretrizes Curriculares Nacionais para la Educación Profesional y Tecnológica. A partir de esos estudios se concluyó que la EPT debe formar para más allá de las demandas del mercado.

Palabras clave: Enseñanza; Evaluación del aprendizaje; Educación Profesional y Tecnológica; Instrumentalización.

\section{Introdução}

No Brasil, a educação tradicional teve seu marco inicial com a educação jesuítica e a publicação do Ratio Studiorum, em 1599. Segundo Saviani (2013), o Ratio Studiorum consistia em um plano geral de estudos constituído por um conjunto de 467 regras, abarcando todas as atividades ligadas ao ensino da época, e que vigorava em todos os colégios da Companhia de Jesus. Para esse autor, as ideias pedagógicas manifestas nesse plano equivalem ao que passou a ser difundido na modernidade como pedagogia tradicional.

$\mathrm{Na}$ abordagem tradicional, o ensino é centrado no professor e está voltado para o que é externo ao educando: o programa, as disciplinas e o próprio professor. Já o educando, é apenas um executor de prescrições que lhe são determinadas por autoridades exteriores (Mizukami, 1986). Quanto à avaliação, esta é realizada tendo em vista a reprodução exata do conteúdo ministrado em sala de aula, prevalecendo a medição, baseada em provas, exames, interrogações do professor, dentre outras (Libâneo, 1994; Mizukami, 1986).

Outra maneira de se perceber a instrumentalização é pela ótica do tecnicismo educacional. Delgado (2015) apresenta duas tipologias antagônicas de modelos educacionais, sendo uma crítica, fundamentada na concepção de educação democrática, com vistas à qualidade social, focada na formação humana plena; e outra, instrumental, assentada na concepção educacional tecnicista, na qual a educação fica subordinada à lógica e aos interesses do mercado.

Na concepção tecnicista, "o elemento principal passa a ser a organização racional dos meios, ocupando o professor e o aluno posição secundária" (Saviani, 2013, p. 382), cabendo ao processo, decidir o que educadores e educandos deverão fazer, e como e quando o farão. Libâneo (2011), destaca que as etapas básicas de um processo de ensino-aprendizagem baseadas no tecnicismo educacional consistem em: estabelecer os comportamentos terminais, por meio de objetivos instrucionais; analisar as tarefas de aprendizagem, com a finalidade de ordenar os passos sequenciais da instrução; fazer cumprir o programa proposto, reforçando gradualmente as respostas corretas relacionadas aos objetivos. Em relação à avaliação, essa concepção, denominada também por Mizukami (1986), de abordagem comportamentalista, busca comprovar se o educando aprendeu e se os objetivos apresentados pelo programa foram atingidos integralmente.

Historicamente, a atual Rede Federal de Educação Profissional, Científica e Tecnológica (RBEPT) tem sido caracterizada como formadora de mão de obra para o mercado de trabalho, portanto, de caráter tecnicista, conforme Cunha (2005); Manfred (2002); Souza \& Rodrigues (2017), em que muitas das políticas que são criadas não estão preocupadas com uma formação ampla do trabalhador.

Nosso objetivo, neste artigo, é problematizar a avaliação da aprendizagem na Educação Profissional e Tecnológica (EPT). Questionamos se essa modalidade de ensino deve ter como prioridade a instrumentalização dos educandos com vistas nas demandas do mercado de trabalho ou proporcionar a estes uma formação mais ampla, de modo a se tornarem sujeitos reflexivos e questionadores. É possível, na EPT, apesar das ideias pré-concebidas de que ela deve ser voltada para a formação de mão de obra, pensarmos numa avaliação para além dessa formação?

Neste sentido, dialogaremos com alguns autores que defendem perspectivas críticas de educação e consequentemente de avaliação, tais como Freire (1989, 1996, 2021), Libâneo (1994, 2011), Lopes e Macedo (2011); Luckesi (1998), Romão (2011); Saul (2015), Ramos (2003), Kuenzer (2004, 2021); Saviani (2013), dentre outros.

O desenvolvimento deste artigo está dividido em outras duas seções seguidas à metodologia. Na primeira, discutimos a respeito da cultura da instrumentalização versus a da emancipação, enfatizando a diferença entre essas duas formas de conceber a avaliação da aprendizagem; posteriormente, destacamos como a avaliação tem sido enfatizada em alguns 
documentos recentes, sobretudo, nas diretrizes que tratam da EPT (fonte: TNR 10 - justificado - espaço 1,5).

\section{Metodologia}

A pesquisa está ancorada em uma abordagem qualitativa, que segundo Creswell (2007, p. 184), “[...] emprega diferentes alegações de conhecimento, estratégias de investigação e métodos de coleta e análise de dados" e preocupa-se com aspectos essenciais, como o reconhecimento e análise de diferentes perspectivas dos participantes e sua diversidade, como também das reflexões dos pesquisadores sobre sua pesquisa e as subjetividades dos sujeitos estudados (Flick, 2004).

Trata-se de uma pesquisa bibliográfica e exploratória. Segundo Gil (2002), "a pesquisa bibliográfica é desenvolvida com base em material já elaborado, constituído principalmente de livros e artigos científicos” (p.44), tendo como principal vantagem o fato de permitir ao investigador a cobertura de uma série de fenômenos muito mais ampla do que aquela que poderia averiguar diretamente. Para esse autor, as pesquisas exploratórias "têm como objetivo proporcionar maior familiaridade com o problema, com vistas a torná-lo mais explícito ou a constituir hipóteses. Pode-se dizer que estas pesquisas têm como objetivo principal o aprimoramento de ideias ou a descoberta de intuições" (Gil, 2002, p. 41).

\section{A cultura da Instrumentalização Versus a Cultura da Emancipação}

A forma como a avaliação da aprendizagem tem sido conduzida em sala de aula, necessita ser repensada e replanejada, para que se desvencilhe do caráter meramente seletista, excludente e instrumental a qual tem sido subordinada, culminando, muitas vezes, em um alto índice de reprovação e evasão escolar (Marinho et al., 2013; Saul, 2015).

De acordo com Saul (2015),

A história da avaliação educacional, em sua dimensão da avaliação do rendimento escolar, ou do aluno, tem sido marcada pela lógica do controle técnico. Nessa, o foco da avaliação é o que o aluno aprendeu, que se expressa pelo domínio de habilidades e conteúdos. A preocupação instrucional tem sido a mais frequente meta do trabalho em sala de aula. Associada à avaliação instrucional estão as avaliações do comportamento, expressas pela exigência de obediência às regras, e a avaliação de valores e atitudes dos alunos (p. 1303, grifo nosso).

Ainda segundo esta autora, o educando sente-se coagido e condicionado pela avaliação, a qual é utilizada pelos professores como forma de dominação dos estudantes, das atividades escolares e dos resultados de aprendizagem, e também como uma "arma" no sentido de conferir um poder disciplinador e ameaçador, adequando-se ao modelo de formação de crianças e adolescentes submissos.

Para Saul (2015), a avaliação educacional enxergada sob este prisma, serve aos intentos de uma educação domesticadora, na qual, de forma passiva, os educandos são colocados frente a conhecimentos prontos e acabados, que lhes são transmitidos ou inseridos em suas mentes, como uma espécie de depósito bancário, sem a pretensão e possibilidade de construir novos conhecimentos que tenham sentido à atividade educativa e que sirvam aos propósitos de uma leitura crítica da realidade, com possibilidades de transformá-la.

Esse processo é resultado de uma educação "bancária", que trata o educando como um "depósitário" e o educador como um "depositador", "enchendo" os educandos de conteúdos, dificultando o pensar verdadeiro (Freire, 2021). Neste sentido,

A concepção e a prática da educação que vimos criticando se instauram como eficientes instrumentos para este fim. Daí que um dos seus objetivos fundamentais, mesmo que dele não estejam advertidos muitos do que a realizam, seja dificultar, em tudo, o pensar autêntico. Nas aulas verbalistas, nos métodos de avaliação dos "conhecimentos", no chamado "controle de leitura", na distância entre o educador e os educandos, nos critérios de promoção, na indicação bibliográfica, em tudo, há sempre a conotação "digestiva" e a proibição ao pensar verdadeiro (Freire, 2021, p. 89, grifos do autor). 
Neste sentido, as concepções pedagógicas que o professor defende são fundamentais para nortear sua prática educativa na hora de avaliar a aprendizagem dos educandos. Por isso, Freire (1996, p. 42, 43) destaca que "a prática docente crítica, implicante do pensar certo, envolve o movimento dinâmico, dialético, entre o fazer e o pensar sobre o fazer". Esse pensar sobre o fazer defendido por Freire, envolve reflexão crítica e um distanciamento da prática docente espontânea e consequentemente, de um saber ingênuo por parte dos educandos, o qual resulta também, em uma "avaliação ingênua".

Desta forma, o compromisso docente não pode resumir-se apenas à transmissão de conteúdos fechados, com ênfase em dados e conceitos desconectados com a realidade dos educandos, tendo em vista primordialmente o cumprimento do programa curricular ao qual está responsável em transmitir, dentro de um cronograma que tem a cumprir, pois, se assim o for, certamente a avaliação não terá resultados satisfatórios (Krasilchik, 2012). Com base nesta acepção, Freire (1996, p. 42, grifos do autor), enfatiza que "a grande tarefa do sujeito que pensa certo não é transferir, depositar, oferecer, doar ao outro, tomado como paciente de seu pensar, a inteligibilidade das coisas, dos fatos, dos conceitos".

É por isso que o foco da avaliação deverá se voltar à aprendizagem dos educandos, valorizando os interesses, as aspirações e as experiências construídas, tendo em vista a diversidade e heterogeneidade presentes em sala de aula. Agindo assim, certamente o professor "enxergará" a avaliação sob outro prisma e procurará, de todas as formas, o melhor caminho para atingir os objetivos propostos. Seguindo esse raciocínio, Krasilchik (2012) sublinha que,

Quando o compromisso é apenas com um corpo de conhecimentos previamente estabelecido, sem consideração pelo nível e heterogeneidade da classe e interesses e capacidades dos alunos, o sistema de avaliação é fechado, priorizando a transmissão de informações, dados e conceitos. Quando o cerne do trabalho é o aluno, levando em conta seus conhecimentos prévios, suas motivações, os níveis cognitivo e afetivo de cada um ou de diferentes grupos na classe, a avaliação deixa de ser um simples aferidor de resultados para ser um meio de melhorar o aprendizado dos alunos e as relações sociais na escola (p.165).

Desta forma, para que este cenário dialógico e emancipador se efetive, faz-se necessário que a mudança na postura pedagógica do professor aconteça não apenas no campo teórico do "dizer", mas acima de tudo, venha influenciar na sua prática, ou seja, no "fazer", em busca de novos parâmetros que assegurem um posicionamento "claro e explícito de tal modo que possa orientar diuturnamente a prática pedagógica, no planejamento, na execução e na avaliação" (Luckesi, 1998, p. 42).

A partir destas reflexões, cabe mencionar que nem sempre o que "está posto no papel" é colocado em prática, ou seja, aquilo que está elencado na maioria dos documentos legais e referendados pelos estudiosos da área, os quais enfatizam que a avaliação deverá ter caráter eminentemente qualitativo, sendo desenvolvida de forma contínua, processual, cumulativa e sob uma perspectiva diagnóstica e formativa, não se efetiva verdadeiramente no contexto da prática, conforme discutido acima.

Isso nos remete às discussões propostas por Lopes e Macedo (2011), a respeito do processo de produção dos textos, os quais estão ancorados no "contexto da influência" e da implementação deles no "contexto da prática", sendo ambos estão permeados por relações de poder.

Conforme Lopes e Macedo (2011),

No caso dos textos curriculares, escritos no que Ball, Bowe e Gold [...] denominam contexto de produção de texto político, estamos tratando de documentos oficiais e de textos legais, mas também, entre outros, de materiais produzidos a partir desses textos, visando à sua maior popularização e aplicação. Há, em sua formulação, interesses e crenças diversos, fazendo com que o(s) projeto(s) sobre o que significa educar, definido(s) no contexto de influência, $\mathrm{seja}(\mathrm{m})$ relido(s) diferentemente pelos sujeitos no momento da representação da política nos textos. Também tal(is) projeto(s) muda $(\mathrm{m})$ de acordo com diferentes eventos e circunstâncias. No geral, produzem-se documentos genéricos, pouco claros, projetando um mundo idealizado (p. 258, 259).

Neste sentido, no contexto de produção e do contexto da prática, muitas vozes são enunciadas disputando lugares de destaque, influenciando assim no resultado final, ou seja, na execução do que foi pensado teoricamente. Por isso, a avaliação 
da aprendizagem está permeada por esses vários discursos que transitam entre o dizer (contexto da influência) e o fazer (contexto da prática).

Por isso, defendemos uma cultura emancipatória de avaliação, que privilegie o dialogismo e a participação dos sujeitos no processo de construção do conhecimento, distanciando-se dos aspectos meramente técnicos e burocráticos do fazer educativo, característicos da educação domesticadora, conforme Saul (2015). Para esta autora,

A opção pela educação domesticadora acaba sendo o carro-chefe que puxa e condiciona a organização curricular, a seleção do conhecimento, os materiais didáticos, os chamados métodos de ensino, o sistema disciplinar, a relação com as famílias, a formação de professores e os processos de avaliação formais e informais, no interior da escola (Saul, 2015, p. 1304).

Freire (1996), ao discutir os saberes necessários à prática educativa na obra Pedagogia da Autonomia, enfatiza as práticas democráticas de avaliação, contrapondo-se a toda e qualquer prática avaliativa autoritária a serviço da domesticação. Para o autor,

Os sistemas de avaliação pedagógica de alunos e de professores vêm se assumindo cada vez mais com discursos verticais, de cima para baixo, mas insistindo em passar por democráticos. A questão que se coloca a nós, enquanto professores e alunos críticos e amorosos da liberdade, não é, naturalmente, ficar contra a avaliação, de resto necessária, mas resistir aos métodos silenciadores com que ela vem sendo às vezes realizada. A questão que se coloca a nós é lutar em favor da compreensão e da prática da avaliação enquanto instrumento de apreciação do que-fazer de sujeitos críticos a serviço, por isso mesmo, da libertação e não da domesticação. Avaliação em que se estimule o "falar a" como caminho do "falar com" (Freire, 1996, p. 130, 131).

Essa maneira de perceber a avaliação é condizente com sua proposta de educação libertadora, estando a serviço de uma intencionalidade democrática, comungando com o dialogismo, um dos princípios centrais da educação dialógica freireana, já que a expressão "falar com” remete à necessidade do diálogo no processo avaliativo.

Desta forma, Saul (2015), destacou algumas características pertencentes à concepção de avaliação emancipatória, dentre as quais, explicita-se:

compromisso com a educação democrática, objetivando práticas de inclusão e desenvolvimento de educandos autônomos; valorização do educando como sujeito do seu processo de aprendizagem; priorização dos aspectos qualitativos do desenvolvimento do educando; proposta de relação pedagógica democrática e horizontal entre educador e educando; valorização do processo e os resultados do ato de ensinar-aprender; utilização de processos dialógicos e participativos; objetivo de melhorar o processo ensino-aprendizagem; objetivo de replanejar a ação educativa (Saul, 2015, p. 1309).

Como se pode observar, a perspectiva de avaliação emancipatória apontada por Saul (2015), privilegia a educação democrática, com práticas inclusivas visando o desenvolvimento da autonomia dos educandos. Estes por sua vez, são percebidos como sujeitos do processo de sua própria aprendizagem, relacionando-se de maneira horizontal junto aos educadores. Quanto ao processo de ensinar-aprender-avaliar, acontece de maneira dialógica e participativa

\section{A Avaliação na EPT: Instrumentalização ou Emancipação?}

Conforme os artigos 205 da Constituição Federal de 1988 e o $2^{\circ}$ da Lei de Diretrizes e Bases da Educação Nacional (Lei $\mathrm{n}^{\circ}$ 9.394/1996), a educação tem por finalidade contribuir para o pleno desenvolvimento do educando, seu preparo para o exercício da cidadania e sua qualificação para o trabalho. Esse tripé deve ser promovido e incentivado com a colaboração da sociedade, tendo a família e principalmente o Estado, o dever de implementá-lo. Oliveira (2013) enfatiza que, 
A Lei 9394/96, ao estabelecer as diretrizes e bases da educação nacional, buscou criar condições legais para que cada escola pudesse se organizar para o alcance dos objetivos propostos na Constituição de 1988 em relação à educação e que espelham o anseio da sociedade brasileira de ter educados todos os seus cidadãos, zelando por medidas de nãoexclusão de alunos pelo sistema escolar, quer pela garantia de vagas, quer pela efetivação de uma aprendizagem bem sucedida (p. 7).

Em seu artigo 24, inciso V, alínea “a”, a LDB destaca que a avaliação deverá ser realizada de forma contínua e cumulativa, prevalecendo os aspectos qualitativos sobre os quantitativos e os resultados obtidos ao longo do período sobre os de eventuais provas finais.

Neste sentido, a avaliação da aprendizagem com caráter formativo tem grande relevância na consecução deste ideário, tendo em vista que ela constitui-se numa atividade complexa que não se resume a aplicações de provas e atribuições de notas, mas, acima de tudo, é fruto de uma reflexão sobre o nível de qualidade do trabalho escolar, tanto dos professores quanto dos alunos, sendo fundamental que ela seja orientada por um processo diagnosticador, mediador e emancipador.

Em relação à EPT, a Resolução CNE/CP nº 1, de 5 de janeiro de 2021, que define as Diretrizes Curriculares Nacionais Gerais para a Educação Profissional e Tecnológica, tratam sobre os aspectos avaliativos apresentando-os na mesma direção da LDB. No entanto, uma leitura mais atenta de um dos artigos da Resolução, traz à tona uma série de incongruências, pois atrela a avaliação ao desenvolvimento de competências. Conforme a Resolução CNE/CP nº 1/2021

A avaliação da aprendizagem dos estudantes visa à sua progressão contínua para o alcance do perfil profissional de conclusão, sendo diagnóstica, formativa e somativa, com prevalência dos aspectos qualitativos sobre os quantitativos, na perspectiva do desenvolvimento das competências profissionais da capacidade de aprendizagem, para continuar aprendendo ao longo da vida (Brasil, 2021, Art. 45, grifo nosso).

Percebe-se que a parte inicial do artigo 45 dialoga com as bases legais da LDB, no entanto, o excerto final enfatiza que a avaliação deve acontecer sob a ótica do desenvolvimento das competências profissionais. Esta forma de conceber a avaliação da aprendizagem está coerente com a Base Nacional Comum Curricular (BNCC), pois há uma mudança de direção, deslocando o foco da aprendizagem, para o desenvolvimento de competências, as quais precisam ser avaliadas sob uma perspectiva de "avaliação das competências", fortalecendo e aprofundando esse tipo de pedagogia que já estava presente, embora de forma mais incipiente, nos antigos Parâmetros Curriculares Nacionais - PCN, da década de 1990.

Diante do exposto, a Resolução CNE/CP nº 1/2021 recebe críticas de vários autores, dentre eles Piolli \& Sala (2021), exatamente pelo fato de estarem alinhadas à Base Nacional Comum Curricular - BNCC e à Reforma do Ensino Médio (Lei nº 13.415/2017). Oliveira (2021), também se posiciona contrariamente, pois afirma que tal documento está permeado por um viés neoliberal e privatista, apresentando um ensino flexível, fragmentado e alinhado ao capital.

$\mathrm{Na} \mathrm{BNCC}$, é explicitado que, ao longo da Educação Básica, os estudantes precisam desenvolver dez competências gerais, que são denominadas pedagogicamente de "direitos de aprendizagem e desenvolvimento". Além disso, cada área de conhecimento e componente curricular de sua respectiva área, dispõem de competências específicas a serem desenvolvidas pelos educandos. Seria, então, mais uma "renovação do velho", remontando ao discurso que havia nas décadas de 1980 e 1990 sobre formação humana, baseada na noção de competências? (Araújo \& Rodrigues, 2010).

Para Ramos (2006),

A idéia que se difunde quanto à apropriação da noção de competência pela escola é que ela seria capaz de promover o encontro entre formação e emprego. No plano pedagógico testemunha-se a organização e a legitimação da passagem de um ensino centrado em saberes disciplinares a um ensino definido pela produção de competências verificáveis em situações e tarefas específicas. Essas competências devem ser definidas com referência às situações que os alunos deverão ser capazes de compreender e dominar. Em síntese, em vez de se partir de um corpo de conteúdos disciplinares existentes, com base no qual se efetuam escolhas para cobrir os conhecimentos considerados mais 
importantes, parte-se das situações concretas, recorrendo-se às disciplinas na medida das necessidades requeridas por essas situações (p. 221).

Dessa forma, avaliar as competências não é um processo simples, já que "a noção de competência ainda é pouco compreendida e coloca problemas reais nos momentos em que os professores se propõem a organizar os currículos, definir estratégias de ensino e proceder a avaliações" (Araújo \& Rodrigues, 2010, p. 58, grifo nosso). Nesse sentido, se entender o que são as competências já é uma tarefa delicada, imaginemos o processo de avaliá-las.

Mas o ponto crucial da discussão, dá-se em relação ao significado de competência mencionado na BNCC, que a entende como a "mobilização de conhecimentos (conceitos e procedimentos), habilidades (práticas, cognitivas e socioemocionais), atitudes e valores para resolver demandas complexas da vida cotidiana, do pleno exercício da cidadania e do mundo do trabalho" (Brasil, 2018, p. 8). Essa conceituação vai de encontro ao que preconizam alguns teóricos que estudam a categoria trabalho-educação, tais como Kuenzer (2004, 2021), Ramos (2003, 2006), dentre outros.

De acordo com Ramos (2006),

A pedagogia da competência passa a exigir, tanto no ensino geral, quanto no ensino profissionalizante, que as noções associadas (saber, saber-fazer, objetivos) sejam acompanhadas de uma explicitação das atividades (ou tarefas) em que elas podem se materializar e se fazer compreender. Essa explicitação revela a impossibilidade de dar uma definição a tais noções separadamente das tarefas nas quais elas se materializam (p. 222).

Em palestra proferida para o Instituto Federal de Educação, Ciência e Tecnologia de Roraima - IFRO, Campus Porto Velho Calama, intitulada: A Educação Profissional e Tecnológica frente à pedagogia das competências, transmitida pelo canal do youtube do IFRO ${ }^{1}$, no dia 25 de junho de 2021, a professora Acácia Kuenzer discutiu pertinentemente o assunto. Para ela, competência é a,

Capacidade de agir, em situações previstas e não previstas, com rapidez e eficiência, integrando conhecimentos tácitos e científicos a experiencias de vida e laborais. Implica a capacidade de solucionar problemas, mobilizando e integrando conhecimentos de forma transdisciplinar a comportamentos e habilidades (Kuenzer, 2021).

A pesquisadora ainda afirma que a competência é uma categoria do mundo do trabalho e não da educação, já que é resultado de uma ação prática. Dessa forma, para ela, não há possibilidade de desenvolver competências na escola, pois a categoria central da escola é o conhecimento. Nesse ponto, Kuenzer discorda da afirmação da BNCC de entender competência como a mobilização de conhecimentos e habilidades. A autora insiste em dizer que "conhecimento não é competência; conhecimento é pré-requisito para que a competência se exerça” (Kuenzer, 2021). Quanto ao conceito de habilidades, a professora destaca que é a ausência de ação consciente, automatismo, ou seja, uma competência automatizada.

Corroborando com estas discussões e sendo também contrária a uma pedagogia das competências esboçada em bases hegemônicas, Ramos (2003) dialoga sobre a possibilidade de se implementar uma pedagogia das competências contrahegemônica, sedimentada sob,

Um referencial teórico-metodológico centrado na práxis humana, mediada pelo trabalho, inicialmente na sua dimensão especificamente econômica - que ordena as finalidades da educação profissional - mas processualmente na sua dimensão ontológica, por tentar potencializar ações emancipatórias pelos trabalhadores (Ramos, 2003, p. 97).

${ }^{1}$ Publicado pelo canal IFRO Campus Porto Velho Calama. Disponível em: https://www.youtube.com/watch?v=NNnfKD1qIok\&ab_channel=IFROCampusPortoVelhoCalama. Acesso em: 25 out. 2021. 
Esse tipo de pedagogia contemplaria práticas curriculares, segundo a autora, que compreendesse o processo de trabalho de maneira totalizante, relacionando os saberes que estruturam as atividades e as relações de trabalho, dentre eles os científicos, técnicos, operacionais, organizacionais e políticos, aos outros saberes relacionados à educação básica, como os das Linguagens, da Matemática, das Ciências Humanas e Sociais e das Ciências da Natureza, tendo em vista a possibilidade de se proceder uma formação unitária, entrelaçando trabalho e cultura, formação geral e profissional, conhecimento científico e técnico.

Em se tratando da Reforma do Ensino Médio, materializada pela Lei 13.415/2017, o que se percebe também é um certo grau de instrumentação sob um viés capitalista/tecnocrático em que o fazer pedagógico está subordinado aos detentores do poder econômico. Isso é discutido por Costa et al. (2018), ao afirmar que,

Manipular a educação para fins instrumentais, alheios às necessidades da vida social dos estudantes, é uma tónica nas modificações realizadas nas orientações para o Ensino Médio por meio da reforma. As alterações impostas preveem que os atores sociais detentores do poder econômico regulem as orientações que subsidiam o fazer pedagógico [...] (p, 178).

Para Costa (2018), o teor da reforma está adequado aos interesses do mercado para a formação de trabalhadores mais flexíveis e na probabilidade de prestação de serviços ao Estado, seja em aluguel de prédios, no oferecimento de serviços educacionais ou em outras situações geradas pela própria reforma.

Partindo desses pressupostos e reportando à nossa questão inicial sobre a possibilidade de pensarmos em uma outra forma de avaliação que vá além da formação de mão de obra especializada para o mercado de trabalho, citamos o exemplo do que consta no Projeto Político-Pedagógico (PPP) do IFRN quanto à orientação dessa instituição para a avaliação da aprendizagem.

Antes disso, consideramos importante lembrar que a palavra projeto vem do latim projectu, que significa "lançar para diante" (Ferreira 1975, p.1.144 apud Veiga, 1995). Para Vasconcelos (2006, p. 17), o PPP, "pode ser entendido como a sistematização, nunca definitiva, de um processo de planejamento participativo, que se aperfeiçoa e se objetiva na caminhada, que define claramente o tipo de ação educativa que se quer realizar, a partir de um posicionamento quanto à sua intencionalidade e de uma leitura da realidade [...]”. Logo, o PPP busca um rumo, uma direção. É uma ação intencional, com um sentido explícito, com um compromisso definido coletivamente. "É político no sentido de compromisso com a formação do cidadão para um tipo de sociedade. [...] Pedagógico, no sentido de definir as ações educativas e as características necessárias às escolas de cumprirem seus propósitos e sua intencionalidade" (Veiga, 1995, p.13).

Algumas características de um PPP são apontadas por Vasconcelos (2006), dentre elas: amplitude, integralidade e globalidade ("guarda-chuva"); de longa duração (o Diagnóstico e a Programação são revistos ano a ano e o Marco Referencial, permanece por 2, 3 ou mais anos); participação da coletividade (democrático); está em permanente (re)construção, pautado no exercício crítico, na avaliação.

Já em relação aos princípios norteadores do PPP, Veiga (1995), elenca: igualdade de condições para acesso e permanência na escola; qualidade, que não pode ser privilégio de minorias econômicas e sociais (combater a repetência e a evasão); gestão democrática (dimensões pedagógica, administrativa e financeira); liberdade (ideia de autonomia); valorização do magistério. Neste sentido, Veiga (1995, p. 19, 20), destaca que,

A qualidade do ensino ministrado na escola e seu sucesso na tarefa de formar cidadãos capazes de participar da vida socioeconômica, política e cultural do país relacionam-se estreitamente a formação (inicial e continuada), condições de trabalho (recursos didáticos, recursos físicos e materiais, dedicação integral à escola, redução do número de alunos na sala de aula etc.), remuneração, elementos esses indispensáveis à profissionalização do magistério. 
Em se tratando das finalidades do PPP, Fortes (2011) e Vasconcelos (2006) são claros: resgatar a intencionalidade da ação, o porquê da escola, o para quê das suas atividades; ser um caminho de transformação da realidade; oferecer um referencial de grupo para a caminhada: planejamento participativo; superar a fragmentalidade das práticas educativas e das práticas autoritárias e/ou individualistas, sendo um canal de participação de todos; diminuir o sofrimento, aumentando o grau de satisfação e realização de todos no ambiente de trabalho; fortalecer o grupo com vistas a enfrentar os possíveis conflitos, contradições, avançando na autonomia e na criatividade; contribuir na formação dos participantes do processo educativo.

Após compreendermos o conceito, as características, os princípios norteadores e as finalidades de um PPP, adentrarmos no universo desse documento elaborado pelo IFRN, estudando-o a fim de se compreender em quais bases epistemológicas ele está assentado, especificamente no que tange à avaliação da aprendizagem.

Já no início do seu texto, no prefácio, consta que o documento construído de forma aberta e dialogal, foi o resultado de um esforço coletivo, a fim de se explicitar as práticas pedagógicas e administrativas que regem essa instituição educativa. Daí o título sugestivo, "Projeto Político-Pedagógico do IFRN: uma construção coletiva".

Em seguida, na introdução, é posto o entendimento do que seja o PPP, o qual

[...] deve ser compreendido como um planejamento global de todas as ações de uma instituição educativa, abarcando direcionamentos pedagógicos, administrativos e financeiros. É um instrumento de gestão democrática que possibilita a reflexão crítica e contínua a respeito das práticas, dos métodos, dos valores, da identidade institucional e da cultura organizacional. Construído de modo participativo, o projeto político-pedagógico permite resgatar o sentido humano, científico e libertador do planejamento. Opõe-se, assim, à lógica do planejamento burocrático ou meramente estratégico, bastante difundido nas esferas mais conservadoras da educação e nas reformas neoliberais dos anos 90. Situado nessa perspectiva emancipatória, o projeto político-pedagógico objetiva, sobretudo, promover mudanças nas concepções e nas práticas cotidianas, traçando diretrizes referenciadoras da caminhada educativa (Instituto Federal de Educação, Ciência e Tecnologia do Rio Grande do Norte [IFRN], 2012, p. 19, grifo nosso).

Como se pode observar, na parte introdutória há uma percepção contra-hegemônica apresentada no documento em relação à cultura, à ciência, à educação e ao planejamento das ações, situando-o em uma perspectiva emancipatória, com a finalidade de promover mudanças nas concepções e práticas cotidianas, traçando novos rumos à trajetória educativa da instituição.

Em se tratando da avaliação da aprendizagem, a subseção 3.5, intitulada "Diretrizes para a prática pedagógica", delineia como deverá acontecer esse processo no IFRN.

O IFRN propõe desenvolver a avaliação numa perspectiva processual, contínua e cumulativa, com preponderância dos aspectos qualitativos sobre os quantitativos, buscando a reconstrução do conhecimento e o desenvolvimento de hábitos e de atitudes coerentes com a formação integral do sujeito. Para tanto, considera o aluno como ser criativo, crítico, autônomo e participativo. Nesse entendimento, a avaliação dos aspectos qualitativos compreende, além da acumulação de conhecimentos (o que remete para a avaliação quantitativa), o domínio do processo de aprendizagem, no que se refere a avanços e recuos, e as possibilidades de autoavaliação e de reorientação no processo (IFRN, 2012, p. 83).

O PPP do IFRN considera também a avaliação da aprendizagem permeada pelas seguintes funções: dialógica, diagnóstica, processual, formativa e somativa. A função dialógica, está ligada a um projeto pedagógico compromissado com as mudanças do meio sociocultural no qual o educando está inserido, tendo em vista a sua emancipação. Na diagnóstica, o intuito é identificar o grau de conhecimentos dos educandos em relação aos conteúdos conceitual, procedimental e atitudinal, a fim de identificar erros e buscar corrigi-los. Na processual, prioriza-se a qualidade e a construção da aprendizagem do educando ao longo do período letivo. Na formativa, busca-se conscientizar o educando em relação às atividades desenvolvidas por ele, para que assim participe de forma consciente, do seu processo formativo, e por fim, na função somativa, explicita-se o resultado referente ao desempenho do aluno, por meio de instrumentos que possibilitem a mensuração da aprendizagem (IFRN, 2012). 
Diante disso, a avaliação da aprendizagem não é compreendida neste documento orientador como uma prática de caráter instrumental e reducionista, mas sim como uma concepção emancipatória, caracterizada "como um processo de descrição, análise e crítica de uma dada realidade, visando transformar essa mesma realidade" (IFRN, 2012, p. 80, 81).

Para Dias Júnior (2009), a avaliação emancipatória, deve promover a participação e o dialogismo entre os sujeitos envolvidos no processo educativo. Dessa forma, "a avaliação deixa de ser um processo de cobrança para se transformar em mais um momento de aprendizagem, tanto para o aluno quanto para o professor" (Romão, 2011, p. 93).

No PPP, está posto que a avaliação deverá estar relacionada com a busca de uma aprendizagem que tenha sentido tanto para o educando, quanto para o educador, já que este necessita estar avaliando constantemente a sua prática pedagógica. Sobre isso, Freire (1989), enfatiza que

Não é possível praticar sem avaliar a prática. Avaliar a prática é analisar o que se faz, comparando os resultados obtidos com as finalidades que procuramos alcançar com a prática. A avaliação da prática revela acertos, erros e imprecisões. A avaliação corrige a prática, melhora a prática, aumenta a nossa eficiência (p. 47).

$\mathrm{O}$ documento também menciona que o educando tem o direito de saber quais conteúdos serão trabalhados nos ambientes da aprendizagem escolar, os objetivos do estudo desses conteúdos, além das estratégias necessárias para que se possam superar as possíveis dificuldades encontradas no percurso formativo, como também, quais os critérios avaliativos serão considerados em relação à aprendizagem dos conteúdos propostos.

Para o alcance deste ideário, é fundamental que o professor utilize instrumentos avaliativos diversos tais como pesquisas, relatórios, seminários, trabalhos em grupo, dentre outros, que dialoguem com a proposta de avaliação dialógica e emancipatória, indo além dos testes e das provas, tão presentes na prática escolar. Tais recursos possibilitarão ao docente acompanhar o desempenho dos educados nas atividades propostas, tomando assim decisões mais acertadas, possibilitando a reorientação dos discentes a partir das dificuldades encontradas, em um permanente processo de ação-reflexão-ação.

Os pressupostos supracitados visam analisar o processo de ensino e aprendizagem em uma perspectiva transformadora da realidade educativa, concebendo a avaliação como um mecanismo dotado de criatividade, de autonomia e de criticidade, indo de encontro à lógica hegemônica da avaliação. A proposta de projetos integradores, no PPP do IFRN, vem ao encontro desse ideário:

O projeto integrador apresenta-se como ferramenta desafiadora, sobretudo para o estudante. Por isso, deve partir da análise de uma problemática calcada em uma visão crítica; deve retratar uma trajetória de pesquisa; deve estimular a criatividade; deve promover a busca por novas descobertas; deve instigar a capacidade de observar e de interpretar as necessidades da sociedade, oportunizando intervenções nas práticas sociais; deve permitir adequação e correção de rumos nas ações planejadas, com base na identificação das necessidades de aprendizagens; e deve implicar a reflexão, da parte dos agentes envolvidos, acerca da gestão dos processos pedagógicos (IFRN, 2012, p. 78).

Entretanto, precisamos estar atentos para o fato de que nem sempre o previsto em um texto se efetiva na prática, como observam Lopes e Macedo (2011). Exercer uma perspectiva integradora pressupõe romper com processos formativos que estão sedimentados, como, por exemplo, a disciplinaridade. Ademais, muitos docentes pouco ou nada conhecem as bases em que se alicerçam a proposta de uma EPT transformadora e terminam por focar nos limites de sua disciplina ou, no máximo, planejar um conteúdo com a participação de colegas de disciplinas de uma mesma área do conhecimento. Daí o porquê de, muitas vezes, os projetos integradores, exigidos nos currículos dos cursos técnicos e superiores do IFRN, não ocorrem de forma exitosa. Isso foi constatado por Santos e Souza (2021), em uma pesquisa com professores e alunos de um curso técnico de nível médio na forma integrada naquela instituição. Os autores, após análise de documentos institucionais e entrevistas com 
servidores e alunos, perceberam incoerências entre o escrito e o feito e um desconhecimento do que deveria ser aquele projeto, que terminou ocorrendo superficialmente, para cumprir com uma exigência da matriz curricular.

\section{Considerações Finais}

Embora a legislação relacionada à educação, norteada pela LDB n $n^{0}$ 9.394/96, enfatize que a avaliação da aprendizagem deve ocorrer de maneira processual, contínua, cumulativa, com prevalência dos aspectos qualitativos sobre os quantitativos, ainda é bem presente em nossas escolas práticas educativas de cunho instrumental, balizadas principalmente em abordagens de ensino tradicionais e tecnicistas.

Neste artigo, discutimos dois tipos de avaliação da aprendizagem: uma perspectiva instrumental, tradicional e tecnicista, em que aspectos como a "medição do conhecimento" e a execução de provas e exames são tidos como centrais, estando o processo educativo restrito à análise de tarefas de aprendizagem com o intuito de se ordenar passos sequenciais da instrução, com ênfase no cumprimento do programa curricular proposto; e um outro, que, ao contrário deste, dá-se sob a égide de um processo de ampliação e de desenvolvimento humano, pautado na perspectiva de uma identidade crítica e emancipatória, contemplando as dimensões culturais, linguísticas, artísticas, sociais, técnicas e tecnológicas. Questionamos qual desses dois tipos de avaliação melhor se adequa à EPT.

Fundamentado em diversos teóricos críticos da educação, fez-se um contraponto entre a cultura avaliativa instrumental e a emancipatória, optando-se por esta última, não só na educação em diversos níveis e modalidades, como também na EPT, já que abre espaço para o diálogo e a participação dos estudantes no processo avaliativo.

Desta forma, faz-se necessário repensar a maneira de se avaliar a aprendizagem em nossas instituições de ensino em geral, e particularmente de EPT, apropriando-se de bons e diversificados métodos avaliativos que subsidiem uma avaliação da aprendizagem com fins de diagnosticar e traçar rumos às aprendizagens futuras, ajudando na formação plena dos educandos. Na EPT, reivindica-se uma avaliação reflexiva e emancipatória capaz de romper com os velhos paradigmas que nortearam essas instituições ao longo de um século e que ainda se mantêm vivos: as práticas de ensino e de avaliação condizentes com as necessidades do mercado, ou seja, das demandas do capital nacional e internacional. Não à toa, vemos, nas últimas décadas a preocupação dos organismos internacionais como o Banco Mundial com a educação no Brasil.

Neste sentido, entendemos que essa discussão é por demais importante, sobretudo pelo fato desta abordagem ser direcionada à EPT, uma modalidade de ensino de grande relevância para o cenário educacional brasileiro e para a formação de sujeitos reflexivos que irão se inserir no mundo do trabalho. No entanto, reconhecemos a necessidade de maior aprofundamento desta temática, discutindo, por exemplo, a avaliação da aprendizagem no âmbito de programas de pósgraduação na área de Educação e de Ensino.

\section{Referências}

Araújo, R. M. L., \& Rodrigues, D. S. (2010). Referências sobre práticas formativas em educação profissional: O velho travestido de novo frente ao efetivamente novo. Boletim Técnico Do Senac, 36(2), 51-63. https://www.bts.senac.br/bts/article/view/218.

Brasil. (1988). Constituição da República Federativa do Brasil. http://www.planalto.gov.br/ccivil_03/constituicao/constituicao.htm.

Brasil. (2006). Lei Darcy Ribeiro (1996). Lei de Diretrizes e Bases da Educação. Senado Federal, Subsecretaria de Edições Técnicas.

Brasil. (2018). Base Nacional Comum Curricular: Educação é a base (versão final). Ministério da Educação. http://basenacionalcomum.mec.gov.br/images/BNCC_EI_EF_110518_versaofinal_site.pdf.

Brasil. (2021). Resolução CNE/CP $n^{\circ} 1$, de 5 de janeiro de 2021. Define as Diretrizes Curriculares Nacionais Gerais para a Educação Profissional e Tecnológica. https://www.in.gov.br/web/dou/-/resolucao-cne/cp-n-1-de-5-de-janeiro-de-2021-297767578.

Creswell, J. W. (2007). Projetos de pesquisa: Métodos qualitativo, quantitativo e misto (2a ed.). Trad.: Luciana de Oliveira da Rocha. Artmed. 
Costa, N. F., Costa, M. G., Costa, P. N., \& Lima, A. C. S. (2018). A instrumentalização da educação brasileira: a reforma do ensino médio. Germinal: Marxismo e educação em debate, 10(3), 176-185. https://doi.org/10.9771/gmed.v10i3.25850.

Cunha, L. A (2005). O ensino de ofícios nos primórdios da industrialização (2a ed.). Editora UNESP; FLACSO.

Delgado, D. M. (2015). Inovação em educação na berlinda: da instrumentalização à emancipação. Linhas Críticas, 21 (46), 764-783. https://www.redalyc.org/pdf/1935/193543849011.pdf.

Dias Júnior, L. D. (2009). Avaliação docente emancipatória: validação de uma ferramenta junto a docentes de computação da UFPA. Novas tecnologias na educação, 7 (1). https://doi.org/10.22456/1679-1916.14032.

Flick, U. (2004). Uma introdução à pesquisa qualitativa (2 $2^{\mathrm{a}}$ ed.). Tradução de Sandra Netz. Bookman.

Fortes, V. G. G. F. (2011). Didática. IFRN Editora.

Freire, P. (1989). A importância do ato de ler: Em três artigos que se completam (23 ${ }^{\mathrm{a}}$ ed.). Autores Associados.

Freire, P. (1996). Pedagogia da autonomia: Saberes necessários à prática educativa. Paz e Terra.

Freire, P. (2021). Pedagogia do Oprimido (78 a ed.). Paz e Terra.

Gil, A. C. (2002). Como elaborar projetos de pesquisa (4 ed.). Atlas.

Instituto Federal de Educação, Ciência e Tecnologia do Rio Grande do Norte. (2012). Projeto Político-Pedagógico do IFRN: Uma construção coletiva. IFRN Ed.

Krasilchik, M. (2012). As Relações Pessoais na Escola e a Avaliação. In A. D. Castro \& A. M. P. Carvalho, (Eds.), Ensinar a ensinar: Didática para a escola fundamental e média (pp. 165-175). Cengage Learning.

Kuenzer, A. Z. (2004). Competência como práxis: os dilemas da relação entre teoria e prática na educação dos trabalhadores. Boletim Técnico Do Senac, 30(3), 81-93. https://www.bts.senac.br/bts/article/view/501.

Kuenzer, A. Z. (2021). A Educação Profissional e Tecnológica Frente à Pedagogia das Competências. https://www.youtube.com/watch?v=NNnfKD1qIok\&ab_channel=IFROCampusPortoVelhoCalama.

Libâneo, J. C. (1994). Didática. Cortez Editora.

Libâneo, J. C. (2011). Democratização da escola pública: A pedagogia crítico-social dos conteúdos (26a ed.). Edições Loyola.

Lopes, A. C., \& Macedo, E. (2011). Contribuições de Stephen Ball para o estudo de políticas de currículo. In S. J. Ball, \& J. Mainardes (Eds.). Políticas Educacionais: Questões e dilemas (1 $1^{\mathrm{a}}$ ed., pp. 248-282). Cortez Editora.

Luckesi, C. C. (1998). Avaliação da aprendizagem escolar ( $7^{\mathrm{a}} \mathrm{ed}$.). Cortez.

Manfredi, S. M. (2002). Educação profissional no Brasil. Cortez.

Marinho, P, Leite, C., \& Fernandes, P. A. (2013). Avaliação da Aprendizagem: um ciclo vicioso de “testinite". Estudos em Avaliação Educacional, 24 (55), 304-334. http://publicacoes.fcc.org.br/ojs/index.php/eae/article/view/2728/2681.

Mizukami, M. G. N. (1986). Ensino: As abordagens do processo. EPU.

Oliveira, Z. M. R. (1998). Avaliação da aprendizagem e progressão continuada: bases para construção de uma nova escola. Estudos em Avaliação Educacional, 18, 7-12. http://publicacoes.fcc.org.br/ojs/index.php/eae/article/view/2249/2204.

Oliveira, T. F. (2021). A educação profissional e tecnológica a partir das novas diretrizes: da precarização à privatização. Educação Profissional E Tecnológica Em Revista, 5(2), 205-228. https://doi.org/10.36524/profept.v5i2.1039.

Piolli, E., \& Sala, M. (2021). A reforma do ensino médio e a educação profissional: da Lei de Diretrizes e Bases (LDB) às Diretrizes Curriculares Nacionais para o Ensino Médio e para a Educação Profissional. Revista Exitus, 11(1), 1-25. https://doi.org/10.24065/2237-9460.2021v11n1ID1543.

Ramos, M. N. (2003). É possível uma pedagogia das competências contra-hegemônica? Relações entre pedagogia das competências, construtivismo e neopragmatismo. Trabalho, Educação e Saúde, 1(1), 93-114. https://www.scielo.br/j/tes/a/sN3qXYKkxSYSQNmr6b7gT6K/?lang=pt\&format=pdf.

Ramos, M. N. (2006). A pedagogia das competências: Autonomia ou adaptação? (4. ed.). Cortez.

Romão, J. E. (2011). Avaliação dialógica: Desafios e perspectivas ( $9^{\mathrm{a}} \mathrm{ed}$.). Cortez.

Saul, A. M. (2015). Na contramão da lógica do controle em contextos de avaliação: por uma educação democrática e emancipatória. Educação e Pesquisa, 41, 1299-1311. https://www.scielo.br/j/ep/a/3nMScNcgg4HFXrrMTTTsGtc/?lang=pt.

Saviani, D. (2013). História das ideias pedagógicas no Brasil (4 ed.). Autores Associados.

Souza, F. C. S., \& Rodrigues, I. S. (2017). Formação de professores para educação profissional no Brasil: percurso histórico e desafios contemporâneos. Revista HISTEDBR On-line, 17 (2), 621-638. https://periodicos.sbu.unicamp.br/ojs/index.php/histedbr/article/view/8644682.

Santos, L. A. S. \& Souza, F. C. S. (2021). Projetos integradores - contributos à práxis pedagógica na educação profissional. Brazil Publishing.

Vasconcelos, C. S. (2006). Coordenação do trabalho pedagógico: Do projeto político-pedagógico ao cotidiano da sala de aula (6a ed.). Libertad Editora.

Veiga, I. P. A. (1995). Projeto político-pedagógico da escola: Uma construção possível. Papirus.

Colocar espaço entre uma referência e outra. Lembre-se que usamos a norma APA. (fonte TNR 8 - espaço simples -justificado) 